\title{
1 Validation of a stochastic temperature \\ 2 generator focusing on extremes and an \\ 3 example of use for climate change
}

\author{
4 Temperature generator, extremes and climate change \\ 5 Parey S.* ${ }^{(1)}$, Hoang T.T.H. ${ }^{(1)}$, Dacunha-Castelle D. ${ }^{(2)}$ \\ 61 EDF/R\&D, 6 quai Watier 78401 CHATOU Cedex, France \\ 72 Laboratoire de Mathématiques, Université Paris 11, Orsay, France \\ 8 Corresponding author : S. Parey Phone : +33 1308776 14, Sylvie.parey@edf.fr \\ 10 ABSTRACT :
}

11 The paper presents a stochastic Seasonal Functional Heteroscedastic Auto-Regressive model

12 developed to simulate daily (minimum, maximum or mean) temperature time series coherent with

13 observed time series and designed to reliably reproduce extreme values through a careful study of

14 the extremes and their bounded character. The model is first validated using different daily

15 minimum and maximum weather-station time series over Eurasia and the United-States in

16 different climatic regions. It is shown that the model is able to produce coherent results both for

17 the bulk of the distribution and for its extremes and especially that it can produce higher or lower

18 extreme values than observed. Then a possible use in the climate change context is tested. It

19 consists in fitting the model over the first part of a long temperature time series and in using it to

20 simulate a large number of possible trajectories for the second part when temperature has

21 increased. Two approaches have been tested to do so, one based on a simple mean change in mean

22 and variance and the other in considering the full seasonalities and trends estimated over the

23 observed second part of the time series. Both approaches have been found to give good results as

24 well for the bulk as for the extremes of the temperature distribution over the second part of the

25 period. However, the second approach allows taking interannual variability changes into account,

26 which leads to more realistic results when this occurs. These results give confidence in the

27 possibility of using this tool as a statistical downscaling tool reliably reproducing temperature

28 extremes.

29 Keywords : daily temperature, stochastic modeling, extremes

\section{Introduction}

31 Weather generators are commonly used in environmental or financial studies as a way to simulate key properties of observed meteorological records and then

33 produce long series of daily weather parameters. Two main approaches can be

34 found in those developments: weather generators are either based on randomly 
1 pooling out analog days in a database of past observations, or on statistically

2 generating the desired variables with a stochastic model whose parameters are

3 estimated on a database of past observations. The advantage of the first approach

4 is a better reproduction of the observed distribution, but the main drawback is that

5 it cannot reproduce non observed values. Although the second approach is based

6 on parametric or semi-parametric definitions of the distributions, its main

7 advantage is its ability to produce physically realistic unobserved situations. This

8 second approach is preferred here as the focus is on extreme events. Most efforts

9 in weather generator developments have been devoted to precipitation (see Wilks

10 \& Wilby 1999 for a review). Precipitation is namely a crucial parameter in many

11 environmental studies and its representation is complicated by its intermittent

12 nature. Here again, different approaches can be found. Cowpertwait et al. (2007)

13 propose a model of storm cells whose occurrence follows a Poisson process and

14 during which rain cells occur as a secondary Poisson process. Other generators are

15 based on different daily states, from the simple dry and wet days to more

16 sophisticated weather type definitions, possibly introduced as a hidden state

17 variable using Hidden Markov Models (Ailliot et al. 2008; Sansom \& Thompson

18 2010). Then, following Richardson (1981), weather generators are developed to

19 represent simultaneously precipitation and other variables like temperature (daily

20 minimum and maximum), solar radiation or wind, for use in agricultural studies

21 essentially. Such models are increasingly used to downscale global climate model

22 results in impact studies (Wilks 1992, Semenov \& Barrow 1997, Wilks \&Wilby

23 1999, Hansen 2002, Kysely \& Dubrovsky 2005, Semenov 2008) because they

24 allow taking variability change into account. The interest in extremes further

25 motivates the use of such models; however they generally must be improved to

26 adequately reproduce extreme events (Furrer \& Katz 2008). Semenov (2008)

27 showed that if precipitation extremes are reasonably well represented by a

28 Richardson type generator (called LARS-WG) temperature extremes are generally

29 not, because the normality assumption used for the residuals is not universally

30 true. Even with the use of weather types and skewed normal distributions

31 (WACS-Gen), Flecher et al. (2010) recognize having difficulties in reproducing

32 extreme events.

33 Stochastic temperature models are also used in the framework of weather

34 derivatives. Weather derivative products provide protections against "weather 
1 risk", that is against the unpredictable component of weather fluctuations, called

2 "weather surprises," or "weather noise." This thus necessitates some knowledge

3 on this "weather noise" over space and time, which motivated the development of

4 stochastic models (Campbell \& Diebold 2005, Mraoua \& Bari 2007, Benth \&

5 Saltyte-Benth 2011).

6 Extreme events are important for industrial adaptation, for installations design as

7 well as for their running. Our goal is then to propose a temperature generator able

8 to correctly reproduce temperature extremes. The general principle of such

9 stochastic models, whatever their usage, consists in modeling the temperature

10 (daily maximum or minimum or mean) as the summation of a deterministic part

11 and a stochastic process, designed to represent the random fluctuations around the 12 mean:

$13 \mathrm{X}(\mathrm{t})=\Lambda(\mathrm{t})+\Phi(\mathrm{t}) \mathrm{Z}(\mathrm{t})$, where $\Lambda(\mathrm{t})$ and $\Phi(\mathrm{t})$ are deterministic and $\mathrm{Z}(\mathrm{t})$ stochastic.

$14 \Lambda(\mathrm{t})$ contains at least a seasonal component, and usually also a trend component.

$15 \Phi(\mathrm{t})$ is most often 1 . The stochastic part generally presents an autoregressive

16 structure, more or less sophisticated: from an AR1 (first order autoregressive) to a

17 GARCH (General Autoregressive Conditional Heteroscedastic).

18 For the proposed model, our basic idea comes from a preliminary analysis of the

19 correlations and especially from the shape of the conditional variance of $Z(t)$

20 when $\mathrm{Z}(\mathrm{t}-1)$ is fixed. In particular, this conditional variance drastically decreases

21 outside of a bounded interval. This leads to the use of a FARCH (Functional

22 AutoRegressive conditional Heteroscedastic) model, the simplest one able to take

23 this behavior into account. FARCH processes are the first order Euler scheme

24 approximation of the discrete Markov chain given by the sequence of discrete

25 observations of a diffusion. Furthermore, the coefficients (drift and diffusion) of

26 the diffusion are those of the FARCH process. Thus we are led to consider

27 temperature as a continuous time process with continuous trajectories. If $\mathrm{X}(\mathrm{t})$ can

28 be assumed as Markovian then the continuous time process is a diffusion. The

29 Markovian property can be tested. This mathematical justification is coherent with

30 the physical interpretation of the heat equation as a diffusion of the thermal

31 energy but also with more general considerations on non linearity and

32 stochasticity which can be found in Sura (2012). The building of the model is

33 based on discrete temperature observations at a given time interval, for instance

34 every day, and the diffusive property has to be translated in this restrictive 
1 framework. The obtained SFHAR (Seasonal Functional Heteroscedastic

2 AutoRegressive) model, with careful treatment of the extreme upper and lower

3 bounds, is described in details in Dacunha-Castelle et al. (2013) and briefly

4 reviewed in the appendix. The present paper focuses on the validation of the

5 model for different climates in Eurasia and in the United-States and proposes a

6 possible application in the climate change context. The model is calibrated on

7 temperature time series starting in 1950 for the United States and Eurasia. It

8 simulates the residuals after accounting for seasonalities and trends in mean and

9 variance.

10 After a brief description of the model and the presentation of the used temperature

11 time series in section 2, section 3 is devoted to the validation of the model for

12 different climates. Then, in section 4, the model is calibrated on the first part of

13 the observed time series, and then, different strategies are tested and validated to

14 simulate the second part, warmer in average than the first one. Discussion and

15 perspectives are proposed in section 5.

\section{2. Model and observations}

17 In the following, $\mathrm{X}(\mathrm{t})$ is the observed temperature time series (either daily

18 minimum or daily maximum temperature), $\mathrm{m}(\mathrm{t})$ its mean trend, $\mathrm{S}_{\mathrm{m}}(\mathrm{t})$ the

19 seasonality of the mean, $s^{2}(t)$ its variance trend, $S_{v}(t)$ the seasonality of the

20 variance and $\mathrm{Z}(\mathrm{t})$ the modeled residual time series.

\section{$21 \quad 2.1$ Brief description of the model}

\section{$22 \quad$ 2.1.1 Pre-processing}

23 As stated before, the model is designed to simulate the residuals $\mathrm{Z}(\mathrm{t})$ from a

24 temperature time series $X(t)$ after accounting for seasonalities $\left(S_{m}(t)\right.$ and $\left.S_{v}(t)\right)$

25 and trends $(\mathrm{m}(\mathrm{t})$ and $\mathrm{s}(\mathrm{t}))$ in mean and standard deviation. The first step is then to

26 identify and remove these deterministic parts from $\mathrm{X}(\mathrm{t})$ to obtain $\mathrm{Z}(\mathrm{t})$. This is

27 done through the following succession of steps:

1) Estimation of the seasonality of $\mathrm{X}(\mathrm{t}): \hat{S}_{m}(t)$

2) Estimation of the trend $\widehat{m}(\mathrm{t})$ from the time series $\left(X(t)-\hat{S}_{m}(t)\right)$

3) Estimation of the seasonality of the variance from $\left[X(t)-\hat{S}_{m}(t)-\right.$ $\widehat{m}(t)]^{2}: \hat{S}_{v}^{2}(t)$ 
4) Estimation of the trend $\hat{s}^{2}(\mathrm{t})$ from the time series $\left[X(t)-\hat{S}_{m}(t)-\right.$ $\widehat{m}(t)]^{2} / \hat{S}_{v}(t)$

5) Finally, $\hat{Z}(t)=\frac{X(t)-\hat{S}_{m}(t)-\hat{m}(t)}{\hat{S}_{v}(t) \hat{s}(t)}$

4 Quantities over headed by a hat correspond to estimations. The identification of

5 seasonality is based on the fitting of a trigonometric function of the form:

$6 \quad \theta_{0}+\sum_{i=1}^{p}\left(\theta_{i, 1} \cos \frac{2 \pi t}{365}+\theta_{i, 2} \sin \frac{2 \pi t}{365}\right)$, and the number $p$ of trigonometric terms is

7 chosen through an Akaike criterion. This parametric identification has been

8 compared to the non parametric STL method (Seasonal Trends decomposition,

9 Cleveland et al. 1990) and both approaches have been found very similar.

10 The trend identification is conducted in a non parametric way by using the

11 LOESS technique (Local regression, Stone 1977). The LOESS estimator is

12 obtained by locally fitting a $\mathrm{d}^{\text {th }}$ degree polynomial to the data via weighted least

13 squares. Throughout this work, the local linear fit is used, which means $d=1$.

14 This method implies the choice of a smoothing parameter, which controls the

15 balance between goodness of fit to the data and smoothness of the regression

16 function. The smoothing parameter is obtained through an automated selection.

17 This selection is difficult here as the data are correlated, non stationary and

18 heteroscedastic. The modified partitioned cross-validation technique proposed in

19 Hoang (2010) is used. It is based on the classical partitioned cross-validation

20 technique of Marron (1987): the observations are partitioned into $g$ subgroups by

21 taking every $g^{\text {th }}$ observations, for example the first subgroup consists of the

22 observations $1,1+g, 1+2 g, \ldots$, the second subgroup consists of the observations

$232,2+g, 2+2 g, \ldots$. The observations in each subgroup are then independent for high

24 g. Chu \& Marron (1991) define the optimal asymptotic bandwidth for Partitioned

25 Cross-Validation in the case of constant variance as $h_{P C V}=h_{0} g^{1 / 5}$, with $\mathrm{h}_{0}$

26 estimated as the minimiser of $P C V_{g}(h)=\frac{1}{g} \sum_{k=1}^{g} C V_{0, k}(h)\left(\mathrm{CV}_{0, \mathrm{k}}\right.$ is the ordinary

27 Cross-Validation score for the k-th group). This approach has been modified to

28 take heterocedasticity into account. Then, the optimal $g$ corresponds to the

29 minimum of a more complicated expression (Hoang 2010) and in practice, it is

30 preferred to estimate $\mathrm{h}_{\text {MPCV }}$ (the optimal bandwidth of the Modified Partitioned

31 Cross Validation) for different values of $g$ and to retain the values of $g$ for which 
$1 \mathrm{~h}_{\text {MPCV }}$ is not too bad (that is not too close to zero and not higher than 0.7 ). For

2 each $g$ the trends $m$ and $s$ are estimated by LOESS with bandwidth $\hat{h}_{M P C V}^{g}$ to

3 obtain an estimator of the expression to minimize. The value of $g$ corresponding

4 to the minimum value is retained, giving the corresponding optimal bandwidth

$5 \mathrm{~h}_{\mathrm{MPCV}}$.

6 The order of estimation of seasonality and trend is not important, it has been

7 checked that estimating trends then seasonality leads to similar results for $Z(t)$.

8 The procedure is illustrated in figure 1.

9 Careful studies of $\mathrm{Z}(\mathrm{t})$ have shown that although seasonality has been removed

10 from the mean and variance, some seasonality remains in the higher order

11 moments like skewness and kurotsis of $\mathrm{Z}(\mathrm{t})$ and in its autocorrelations. However,

12 no significant remaining trends could have been found in high order moments,

13 autocorrelations or extremes of $\mathrm{Z}(\mathrm{t})$.

\section{$14 \quad$ 2.1.2 Model for $Z(t)$}

15 The proposed model is described in detail in Dacunha-Castelle et al. (2013) and

16 summarized in the appendix. The first step is to estimate the extremes of $Z(t)$. The

17 upper and lower bounds $r_{1}$ and $r_{2}$, together with the corresponding shape

18 parameters $\xi_{1}$ and $\xi_{2}$ are estimated by fitting a GEV distribution to the minima

19 and the maxima of $\mathrm{Z}(\mathrm{t})$ respectively. The extremes of $\mathrm{Z}(\mathrm{t})$ do not show any clear

20 seasonality and the fitting is done with 73-day blocks (5 blocks per year).

21 Sensitivity tests on the choice of block length showed that the results do not

22 significantly differ. The shape parameter is negative, thus the distributions are

23 bounded. However, if it is too close to 0 , the simulation may be problematic. If

24 this happens, it is advised to slightly change the block length in order to get a

25 better estimate of this parameter.

26 Then the proposed model is justified. It consists of a modification of a Seasonal

27 Functional Heteroscedastic AutoRegressive model of the form:

$$
Z(t)=b Z(t-1)+a(t, Z(t-1)) \varepsilon_{t}, \varepsilon_{\mathrm{t}} \text { being a normal distribution with } 0
$$

29 mean and unit variance, and:

$$
b=\theta_{0}+\sum_{j=1}^{p_{1}}\left(\theta_{j, 1} \cos \frac{2 \pi t}{365}+\theta_{j, 2} \sin \frac{2 \pi t}{365}\right), \mathrm{p}_{1} \text { being chosen by an Akaike }
$$

31 criterion, because seasonality remains in the autocorrelation, and $a$ is estimated as

32 a degree 5 trigonometric polynomial: 
2 under constraints $\left(a^{2}\right)^{\prime}\left(r_{1}\right)=\frac{2 b\left(r_{1}\right)}{1-1 / \xi_{1}} ;\left(a^{2}\right)^{\prime}\left(r_{2}\right)=\frac{2 b\left(r_{2}\right)}{1-1 / \xi_{2}}$ and $a^{2}(t)>0 \forall t$, with

$3 \mathrm{p}_{2}$ chosen by an Akaike criterion, $\mathrm{r}_{1}$ and $\mathrm{r}_{2}$ being respectively the lower and upper

4 bound of the extreme value distributions of $Z(t)$ and $\xi_{1}$ and $\xi_{2}$ the corresponding

5 shape parameters. The form of $a$ and the constraints are given by the extreme

6 value theory of the continuous time process (Davis 1982). In practice, the

7 autoregressive part of $\mathrm{Z}(\mathrm{t})$ is first estimated, then $a$ is estimated from

$8 \quad(Z(t)-\hat{b} Z(t-1))^{2}$ by maximum likelihood with constraints.

9 Once the parameters have been estimated, as many sequences of $Z(t)$ as desired

10 can be simulated with the model. A sequence consists of a certain number of years

11 and each day $\mathrm{t}, \mathrm{Z}(\mathrm{t})$ is computed from $\mathrm{Z}(\mathrm{t}-1)$. The initial value is randomly

12 selected from the observed residuals. A condition is added to insure that each $\mathrm{Z}(\mathrm{t})$

13 remains inside the limit bounds $r_{1}$ and $r_{2}$ : if the simulated value at time $t$ exceeds

14 the upper bound or is lower than the lower bound, it is disregarded and another

15 value for $\mathrm{Z}(\mathrm{t})$ is computed from $\mathrm{Z}(\mathrm{t}-1)$. This is equivalent to a modified model

16 where the distribution of $\varepsilon_{t}$ is a truncated normal distribution whose truncation

17 depends on the value of $\mathrm{Z}(\mathrm{t}-1)$ (its values are $\frac{r_{1}-b \mathrm{Z}(\mathrm{t}-1)}{a(\mathrm{Z}(\mathrm{t}-1))}$ and $\left.\frac{r_{2}-b \mathrm{Z}(\mathrm{t}-1)}{a(\mathrm{Z}(\mathrm{t}-1))}\right)$. Thus the

18 obtained simulated residuals are bounded.

19 Then a simulation of the initial temperature time series is obtained by re-

20 introducing the estimated deterministic parts $\hat{S}_{m}(t), \hat{m}(t), \hat{S}_{v}(t)$ and $\hat{s}(t)$. As an

21 indication, 100 simulations of a 60 -year daily time series need around $7 \mathrm{mn}$ of

22 computing time on a standard laptop.

23 Compared to most generators found in the literature, our model differs in its

24 bounded property and in the careful retrieval of the smoothing parameter to

25 compute the non parametric trends in both mean and variance to obtain the then

26 simulated residuals. The main consequence is thus that the simulated time series'

27 length is at most that of the observed one used to determine the trends. But as

28 many equivalent time series as desired can be computed, giving a similarly rich

29 sample. The optimal smoothing parameter is linked to interannual variability,

30 which allows an indirect consideration of this property of temperature time series 
1 besides daily variance. Furthermore, the auto-correlations are fully seasonal and

2 the behavior of the extremes is carefully introduced in the volatility (or lag 0 auto-

3 correlation) coefficients $a(\mathrm{t})$. This is expected to really improve the ability of the

4 model at reproducing extremes, which will be examined in this paper.

\section{$5 \quad 2.2$ Observed time series}

6 The validation of the model is conducted for different climates in Eurasia and in

7 the United-States. For Eurasia, weather station time series of daily minimum

8 temperature (TN) and daily maximum temperature (TX) are obtained from the

9 ECA\&D project database. The project gives indications of homogeneity through

10 the results of different break identification techniques (Klein Tank et al. 2002).

11 First, the series which could be considered as homogenous (stated as "useful" in

12 the database) over the period1950-2009 have been selected for both TN and TX.

13 Then, only the time series with less than 5\% missing data are kept, leading to 106

14 series for TX and 120 for TN (many TX series, mostly in Russia, have missing

15 values from 2007 onward whereas the corresponding TN ones have missing

16 values only in 2009).

17 For the United States, weather station TX and TN time series are obtained from

18 the Global Historical Climatology Network - Daily Database (GHCN daily)

19 (Menne et al. 2011). A similar selection procedure left us with 86 series for TX

20 and 85 for $\mathrm{TN}$.

21 Among these time series, 4 weather stations corresponding to different climates,

22 in terms of mean annual temperature, have been chosen for each continent, as

23 listed in table 1. As stated before, the weather station of Olekminsk in Russia

24 cannot be considered for TX as it exhibits too many missing values. No other

25 station with a similar climate to that of Olekminsk is available for TX.

\section{3. Validation}

27 For each of the 7 (for TX) or 8 (for TN) temperature time series, the parameters of

28 the model are fitted over the whole period length. Then, 100 simulations of the

29 model are computed for each location and the results are compared to the

30 observed time series both for the representation of the bulk of the distribution and

31 of its warm and cold extremes. 


\section{$1 \quad 3.1$ Bulk of the distribution}

2 Table 2 and 3 summarize the comparison of the mean, variance, skewness and

3 kurtosis of the distributions of each temperature time series obtained from the

4 observations and from the 100 model simulations (mean value and $95 \%$

5 confidence interval). The results show that these different moments of the

6 observed distribution of daily maximum or minimum temperature are correctly

7 reproduced by the stochastic simulations, although the higher moments are

8 sometimes less accurately reproduced. This good result may be linked to the

9 domination of the annual cycle, thus the seasonal distributions have been

10 compared too. Figure 2 shows the Q-Q plots of observed and simulated winter and

11 summer distributions of TN in Olekminsk and TX in Death Valley. Similar results

12 for the other stations confirm that the model reasonably reproduces the seasonal

13 temperature distributions.

14 Figure 3 shows that the mean annual cycle, as well as that of the standard

15 deviation, is faithfully represented. Figure 3 is for TN in Berlin and TX in

16 Jacksonville, but similar results are found for each individual time series.

17 Kolmogorov-Smirnov tests have been applied to compare the distributions

18 obtained for each day of the year between observations on the one hand and

19 simulations on the other hand, and they show that the distributions can be

20 considered as similar with a 95\% confidence level. The proposed stochastic model

21 is thus able to correctly reproduce the bulk of the daily minimum or maximum

22 temperature distributions for different climates.

\section{$23 \quad 3.2$ Extremes}

24 The model is constructed for a bounded variable and the simulations are made in

25 such a way that each simulated value remains inside the estimated bounds of the

26 residuals. Thus first, the Generalized Extreme Value (GEV) distribution

27 parameters for the simulated residuals are compared to those of the observed ones,

28 both for the lowest and the highest extremes. Figure 4 shows the distributions for

29 each parameter (location $\mu$, scale $\sigma$ and shape $\xi$ ) obtained from the 100

30 simulations for the highest (warm) extremes (upper panels) and the lowest (cold)

31 extremes (lower panel) together with the same parameters obtained from the

32 observed residuals (red line) for TN in Berlin and TX in Death Valley. The results

33 show, and this is true for the other temperatures and locations too, that the shape 
1 parameter is generally better reproduced in the simulations than the location and

2 scale parameters. It can be mathematically proven that the proposed stochastic

3 model is able to produce the correct shape parameter when a truncated normal

4 distribution is used for $\varepsilon_{t}$.

5 Then table 4 compares the 50-year Return Levels (RL) of the maxima of TX and

6 the minima of $\mathrm{TN}$ for the different locations over the whole observation period.

7 The estimation is made by fitting a GEV to the block maxima of summer TX or

8 winter TN (Coles 2001) with the maximum likelihood method and considering the

9 choice of 2 blocks per season as a reasonable bias / variance compromise. The

10 estimation is conducted as if the extremes would not present trends over the entire

11 period, which is of course wrong, but it simplifies the computations and is

12 sufficient to give a first view of the representation of the extremes by the proposed

13 model. For each of the 100 simulations, the 50-year RL is computed. The given

14 confidence interval is obtained as the $2.5^{\text {th }}$ and $97.5^{\text {th }}$ percentiles of the

15 distribution of the $100 \mathrm{RLs}$, whereas for the observations the confidence interval

16 is the $95 \%$ one given by the delta-method (that is based on the asymptotic

17 normality of the maximum likelihood estimators). Generally, the simulations give

18 higher warm RLs and lower cold RLs than observed, but the confidence intervals

19 obtained from the observations generally show some overlapping with the $2.5^{\text {th }}$

20 and $97.5^{\text {th }}$ percentiles of the distribution obtained from the simulations (except for

21 TX in Glasgow and TN in Petropavslosk). The fact that the model produces

22 higher (or lower for cold temperature) extremes than observed is not surprising

23 because the simulations produce 100 possible realities, among which higher or

24 lower extremes could have been observed. This thus shows that the model is not

25 only able to produce extremes, but also to produce more extreme extremes than

26 observed, which is interesting.

27 Finally, the ability of the model to produce heat or cold waves has been

28 investigated. Cold waves are defined as periods of consecutive days with daily

29 minimum temperature lower than the $2^{\text {nd }}$ percentile and heat waves as periods of

30 consecutive days with daily maximum temperature above the $98^{\text {th }}$ percentile. The

31 number of consecutive days varies between 1 and 15 days, the last class

32 corresponding to the few episodes with more than 15 days, if any. Thus for each

33 location the $2^{\text {nd }}$ and $98^{\text {th }}$ percentiles of the observed time series are computed and

34 the distribution of episodes in the observed time series is compared to the 
1 minimum, maximum and mean frequencies of such a distribution in the 100

2 simulations. Figure 5 shows the results for cold waves in Petropavslovsk and heat

3 waves in Charleston. Even though the stochastic model tends to overestimate the

4 proportion of 1-day cold excursions compared to the observations, it is still able to

5 produce longer episodes in a reasonable proportion, even the longest ones. This

6 tendency to overestimate the frequency of 1-day events is less systematic for heat

7 waves.

\section{4. Possible use in the climate change context}

9 The previous section has shown that the proposed stochastic model, when fitted

10 on a temperature time series, is able to correctly reproduce the bulk of the

11 distribution as well as the extremes of the studied time series. This is an

12 interesting result as far as the model allows reliable simulations of a high number

13 of possible temperature evolutions at a given location giving access to potential

14 unobserved but still possible levels. In the climate change context, it could also be

15 very interesting to produce possible temperature evolutions for the future, given

16 that climate is warming. General or regional climate models are designed to allow

17 such projections for the different climatic variables, but their ability to represent

18 extreme values for a precise location is still questionable. Thus different

19 downscaling techniques, from simple bias corrections to full dynamical

20 downscaling with limited area models, are explored (Maraun et al. 2010). The aim

21 here is to check whether the proposed stochastic model can be used as a statistical

22 downscaling tool giving reliable indications on temperature extremes.

\section{$23 \quad 4.1$ Simulation procedure}

24 To do so, among the previously used temperature time series, two have been

25 selected as showing an identifiable break in the evolution of mean temperature,

26 splitting the time series in two sub-series of roughly similar length. Break is

27 identified using the Mudelsee (2009) method which consists in selecting the date

28 for which the standard deviation of the residuals resulting from the two-phase

29 regression model is the minimum, after having considered all dates (except the

30 first and last 5 ones, to avoid edge effects) as potential break points. This simple

31 technique is used because the identification of the break is not the ultimate goal of

32 the work but is only made for the sake of illustration. More general regression 
1 techniques exist, such as the segmented regression proposed by Muggeo (2003).

2 Such a break is identified in year 1980 for TN in Berlin and in year 1985 for TX

3 in Death Valley for both the mean and variance evolutions.

4 Then, each time series is split into two shorter time series: 1950-1980 and 1981-

52009 for TN in Berlin and 1962-1985 and 1986-2009 for TX in Death Valley. For

6 both sub series, the residuals $Z(t)$, after removing trends and seasonalities in mean

7 and variance, are estimated. The parameters of the stochastic model defined to

8 simulate $\mathrm{Z}(\mathrm{t})$ are fitted over the first sub-series in each case. Then, the

9 reconstruction of the desired temperature time series for each period necessitates

10 that trends and seasonalities are added to the simulated residuals. Two ways are

11 compared to compute the desired temperature time series over the second (and

12 warmer) sub period:

13 1) Average mean and variance changes are added to the trends computed from the first sub period: if $m_{1}$ is the mean over the first period, $s_{1}$ the standard deviation, and $\mathrm{m}_{2}$ and $\mathrm{s}_{2}$ the same quantities for the second period: $X_{2}(t)=\hat{S}_{m_{1}}(t)+\widehat{m}_{1}(t)+\left(m_{2}-m_{1}\right)+\hat{S}_{v_{1}}(t) * \hat{S}_{1}(t) * \frac{s_{2}}{s_{1}} *$ $Z(t)$, where $\hat{S}_{m_{1}}(t), \widehat{m}_{1}(t), \hat{S}_{v_{1}}(t)$ and $\hat{s}_{1}(t)$ are the seasonalities and trends estimated over the first sub period. Table 5 summarizes the means and variances of each sub series.

2) Seasonalities and trends are those computed over the second sub period: $X_{2}(t)=\hat{S}_{m_{2}}(t)+\widehat{m}_{2}(t)+\hat{S}_{v_{2}}(t) * \hat{S}_{2}(t) * Z(t)$ where $\hat{S}_{m_{2}}(t), \hat{m}_{2}(t), \hat{S}_{v_{2}}(t)$ and $\hat{s}_{2}(t)$ are the seasonalities and trends

24 In the first way, interannual variability, included in the smoothing parameter of

25 the non parametric trends, remains that of the first period, whereas the second 26 approach allows taking interannual variability of the second period into account.

\section{$27 \quad 4.2$ Results}

\subsubsection{Bulk of the distribution}

29 As previously, the first comparisons aim at validating the reproduction of the

30 main characteristics of the bulk of the distribution. Table 6 gives the observed and

31 simulated mean and variance obtained for the second period in winter and in

32 summer with each of the used approach for each location and variable. As 
1 expected, approach 2, which takes trends and seasonalities of the second period

2 into account, gives better results, but the results given by the first approach are

3 close to the observations too. Figure 6 gives a better view of the entire

4 distribution: it presents, for different percentiles (from the very low $1 \%$ to the very

5 high $99 \%$ through the median), the distribution of such percentiles obtained from

6 the 100 simulations in black and the values obtained from the observations in red.

7 It shows that for all percentiles, the observed estimates fall inside the distributions

8 of the simulated estimates, whatever the approach taken for the simulations. This

9 thus validates the two approaches to compute the distribution of temperature for a

10 future period when mean and variance have changed.

$11 \quad 4.2 .2$ Extremes

12 Let us now look at the extremes, in terms of 50-year return levels and of heat or

13 cold waves. Table 7 gives the obtained 50-year return levels for period 2, again in

14 considering the series as stationary, and estimated from the observations and from

15 each type of simulation. As in the previous section, the $95 \%$ confidence interval

16 for the observations is computed with the delta-method while for the simulations,

17 the $2.5^{\text {th }}$ and $97.5^{\text {th }}$ percentiles of the distribution of the estimated 100 50-year RLs

18 are taken. The results show that for Berlin, approach 2 gives slightly better results

19 than approach 1 whereas for Death Valley this is not the case. This can be

20 explained by the fact that the smoothing parameter computed to estimate the mean

21 and variance trends is the same for both periods for Death Valley (0.08) whereas

22 for Berlin it changes from 0.32 in the first period to 0.08 in the second one. Thus,

23 in Berlin, interannual variability for daily minimum temperature is higher in the

24 second period, and taking this into account logically improves the simulations.

25 Figure 7 shows the distributions of cold waves in Berlin and heat waves in Death

26 Valley according to each simulation procedure in the same way as figure 5 in the

27 previous section. Here, both approaches give similarly good results.

\section{Conclusion and perspectives}

29 In this paper, a stochastic Seasonal Functional Heteroscedastic Auto-Regressive

30 model for daily temperature has been presented and validated for different

31 climates in Eurasia and in the United States. 
1 First, it has been shown that when fitted over a long temperature series (daily

2 minimum or maximum) and used to simulate a large number of equivalent

3 trajectories, the model is able to correctly reproduce both the bulk and the

4 extremes of the observed distribution. In particular, it is able to produce higher or

5 lower extremes than observed.

6 Then, for two temperature time series for which a break in the evolution of both

7 mean and variance could have been identified around the middle of the period, the

8 model has been constructed over the first part of the period and used to reproduce

9 the second part. As the model simulates the residuals after accounting for trends

10 and seasonalities in mean and variance, the reconstruction of the observed

11 variable for any period consists in re-introducing this information on trends and

12 seasonalities. Two approaches have been tested: firstly taking global mean and

13 variance changes between both periods into account (like in the so-called "delta

14 method") and secondly introducing the real trends and seasonalities computed

15 over the second period. The second approach allows taking interannual changes

16 into account if any occurs. This is the case for the daily minimum temperature

17 time series in Berlin and then, this last approach improves the results. Both

18 approaches however give equivalently good results, both in terms of bulk of the

19 distribution as in terms of extremes.

20 This sounds encouraging in the perspective of using this tool as a downscaling

21 technique suitable to deal with temperature extremes. The second approach

22 particularly, opens the possibility of taking possible interannual variability

23 changes into account. We can imagine for example that the model is fitted over an

24 observed temperature time series representative of a location of interest and then,

25 future temperatures for this location can be obtained by introducing the

26 seasonalities and trends estimated over a corresponding, suitably corrected, grid

27 point time series produced by different climate models with different scenarios.

28 Present results show that this technique is able to give reliable information for the

29 temperature extremes, for highest or lowest values as well as episodes. However,

30 further studies will be devoted to hot and cold episodes. Although the model is

31 able to produce long cold or heat waves, it should be able to produce more of such

32 events among 100 simulations. Here the autocorrelation coefficient has been

33 considered periodic, but it is suspected that it may increase once a certain high or

34 low threshold is crossed. This will be further investigated. In a broader 
1 perspective, the model could be part of a more general weather generator in

2 addition with a rainfall generator for example.

\section{Appendix: model description}

5 Before choosing a model for the reduced process $\mathrm{Z}(\mathrm{t})$, after removal of trends and

6 seasonalities in mean and variance, its correlations and conditional variance have

7 been analyzed. The non parametric analysis of the conditional variance of $Z(t)$

8 given $\mathrm{Z}(\mathrm{t}-1)$ shows a particular behavior: linear in the core of the distribution,

9 close to zero for very high and low values of $\mathrm{Z}(\mathrm{t}-1)$, the conditional mean being

10 close to a linear function. The first idea is thus to choose a FARCH model with

11 finite bounds for the distribution. The application of the extreme theory is not

12 justified at this step (because a mathematical theory does not exist for these

13 processes) but it gives, once done, a negative shape parameter $(\xi<0)$ that suggests

14 a bounded distribution.

15 The idea is then to choose a modified FARCH model

$16 Z(t)=b(Z(t-1))+a(Z(t-1)) \varepsilon_{t}$ where $\varepsilon_{t}$ is a truncated Gaussian noise whose

17 bounds depend on the value of $\mathrm{Z}(\mathrm{t}-1)$. The second step is then to represent the

18 temperature as a continuous time process (with continuous trajectories). The

19 FARCH processes are the first order Euler scheme approximation of the discrete

20 Markov chain $\mathrm{M}$, where $\mathrm{M}(\mathrm{t})$ is the observation at time $\mathrm{t}$ of the continuous

21 diffusion given by: $d Y(t)=b(t, Y(t))+a(t, Y(t)) d W(t)$ where $b$ is the drift,

$22 a$ the diffusion coefficient and $\mathrm{W}(\mathrm{t})$ a Brownian motion. The estimation of the

23 coefficients of such a continuous stationary diffusion is commonly done using its

24 first order Euler scheme Z, thus a FARCH process with the same functional

25 coefficients. Technically this situation is very informative in relation with the

26 extremes theory. From the geometric ergodicity of the diffusion, the extreme

27 parameters and the bounds of the continuous time process can be estimated using

28 only the chain M. Z is from now considered as an approximation of M. Now we

29 use the continuous process as a tool. The extremes coefficients and thus the

30 bounds $r_{1}$ and $r_{2}$ are estimated by fitting a GEV distribution to the maxima of the

31 reduced series here modeled as $\mathrm{M}(\mathrm{t})$. The support of $\mathrm{M}(\mathrm{t})$, say $\left(\mathrm{r}_{1}, \mathrm{r}_{2}\right)$, is bounded

32 so that $r_{1}$ and $r_{2}$ are inaccessible boundary points for $Y$. At the boundary, we have:

1. $a$ and $b$ are defined and continuous on $\left[\mathrm{r}_{1}, \mathrm{r}_{2}\right]$

$34 \quad 2 . \quad b\left(r_{1}\right) b\left(r_{2}\right) \neq 0$ 
1 Under hypotheses 1. and 2. and $\xi<0$, we prove in Dacunha-Castelle et al. (2013)

2 the following theorem:

3 If the distribution of the maximum of the diffusion $\mathrm{Y}$ is in the domain of attraction

4 of a GEV distribution with $\xi<0$ then the marginal distribution is common to the

5 chain $\mathrm{M}$ and to $\mathrm{Y}$ and so they are in the same domain of max attraction.

6 We have the following behavior of $a$ as $\mathrm{x} \rightarrow \mathrm{r}_{2}$ :

$$
\mathrm{a}^{2}(\mathrm{x})=-2 \mathrm{~b}\left(\mathrm{r}_{2}\right) \xi^{\prime}\left(\mathrm{r}_{2}-\mathrm{x}\right)+\mathrm{o}\left(\mathrm{r}_{2}-\mathrm{x}\right) \text { where } \xi^{\prime}=\frac{\xi}{\xi-1}
$$

This information is then plugged-in as constraints in the likelihood of the Euler

9 scheme to estimate coefficients $a$ and $b$ with bound constraints.

\section{Acknowledgements}

11 The authors acknowledge the data providers in the ECA\&D project (http://eca.knmi.nl) and in the

12 National Climatic Data Center in NOAA (www.ncdc.noaa.gov). They also would like to thank the 13 reviewers whose proposals helped improving the paper.

\section{References}

16 Ailliot P, Thompson C, Thomson P (2008) Space time modelling of precipitation using a hidden Markov model and censored Gaussian distributions. Journal of the Royal Statistical Society.

Benth EF \& Saltyte Benth J (2011) Weather Derivatives and Stochastic Modelling of Temperature. International Journal of Stochastic Analysis.

Campbell SD \& Diebold FX (2005) Weather forecasting for weather derivatives. Journal of the American Statistical Association. Vol. 100, N469, pp 6-16, Applications and case studies, DOI 10.1198/016214504000001051

Cleveland RB, Cleveland WS, Mcrae JE, \& Terpenning I. (1990): Stl: a seasonal-trend decompostion procedure based on loess (with discussion). Journal of Official Statistics, 6:3-73.

Chu C K \& Marron J S (1991) Comparison of two bandwidth selectors with dependent errors. Annals of Statistics. 19: 1906-1918

Coles S (2001) An introduction to statistical modeling of extreme values, springer series in statistics. Springer Verlag, London

Cowpertwait P, Isham V, Onof C (2010) Point process models of rainfall: developments for finescale structure. Proceedings of the Royal Society. A 463, 2569-2587, doi:10.1098/rspa.2007.1889

Dacunha-Castelle D, Hoang TTH, Parey S (2013) Modeling of air temperatures: preprocessing and trends, reduced stationary process, extremes, simulation. Journal of the French Statistical Society, accepted for publication.

Davis RA (1982). Maximum and minimum of one-dimensional diffusions. Stochastic Processes and their applications, 13:1-9.

Flecher C, Naveau P, Allard D, Brisson N (2010) A Stochastic Weather Generator for skewed data. Water Resources Research. Vol. 46, 7, doi:10.1029/2009WR008098 
Furrer EM \& Katz RW (2008) Improving the simulation of extreme precipitation events by stochastic weather generators. Water Resources Research, Vol. 44

Hansen JW (2002) Realizing the potential benefits of climate prediction to agriculture: issues, approaches, challenges. Agric Syst 74:309-330

Hoang TTH (2010) Modélisation de séries chronologiques non stationnaires, non linéaires: application à la définition des tendances sur la moyenne, la variabilité et les extrêmes de la température de l'air en Europe. PhD thesis work (written in English), http://www.tel.archivesouvertes.fr/tel-00531549/fr/

Klein Tank AMG et al. (2002) Daily dataset of 20th-century surface air temperature and precipitation series for the European Climate Assessment. International Journal of Climatology 22:1441-1453. Data and metadata available at http://eca.knmi.nl

Kysely J, Dubrovsky M (2005) Simulation of extreme temperature events by a stochastic weather generator: effects of interdiurnal and interannual variability reproduction. International Journal of Climatology 25:251-269

Maraun D, Wetterhall F, Ireson AM, Chandler RE, Kendon EJ, Widmann M., Brienen S., Rust HW, Sauter T, Themeß M., Venema VKC, Chun KP, Goodess CM, Jones RG, Onof C, Vrac M, Thiele-Eich I (2010) Precipitation downscaling under climate change: Recent developments to bridge the gap between dynamical models and the end user, Reviews of Geophysics, 48(3), DOI: 10.1029/2009RG000314

Marron JS (1987) Partitioned cross-validation. Econometric Review, 6 :271-284.

Menne MJ, Durre I, Vose RS (2011) An overview of the Global Historical Climatology Network Daily Database. Journal of Applied Meteorology and Climatology

Mraoua M \& Bari D (2007) Temperature stochastic modelling and weather derivatives pricing: empirical study with Moroccan data. Afrika Statistika. Vol. 2, N ${ }^{\circ} 1 \mathrm{pp} 22-43$

Mudelsee M (2009) Break function regression. The European Physical Journal Special Topics, 174:49-63

Muggeo VMR (2003) Estimating regression models with unknown break-points. Stat. Med., 22, 3055-3071.

Richardson CW (1981) Stochastic simulation of daily precipitation, temperature, and solar radiation. Water Resources Research. 17, 182-90.

Sansom J \& Thompson P (2010) A hidden seasonal switching model for high-resolution breakpoint rainfall data. Water Resources Research Water Resources Research. Vol. 46, 8, doi:10.1029/2009WR008602

Semenov MA (2008) Simulation of extreme weather events by a stochastic weather generator. Climate Research. Vol. 35: 203-212

Semenov M. \& Barrow EM (1997) Use of a stochastic weather generator in the development of climate change scenarios. Climatic Change 35, 397-414.

Semenov MA \& Brooks RJ (1999) Spatial interpolation of the LARS-WG stochastic weather generator in Great Britain. Climate Research. Vol. 11: 137-148

Stone C. J. (1977), Consistent nonparametric regression. Annals of Statistics, 5: 595-620

Sura P (2012) Stochastic Models of Climate Extremes: Theory and Observations. In Extremes in a Changing Climate: Detection, Analysis and Uncertainty, edited by A. AghaKouchak, D.

60 Easterling, K. Hsu, S. Schubert, and S. Sorooshian, Springer, doi: 10.1007/978-94-007-4479-0 2. 
1 Wilks DS (1992) Adapting stochastic weather generation algorithms for climate change studies. 2 Climatic Change, 22: 67-84

4 Wilks DS \& Wilby RL (1999) The weather generation game: a review of stochastic weather 5 models. Progress in physical geography. 23,3 pp 329-357

6 
List of tables

Table 1: presentation of the considered temperature time series: period lengths and mean observed temperature

Table2: mean, variance, skewness and kurtosis estimated from observed and simulated daily maximum temperature (TX) time series. For the simulations, the mean values with the $95 \%$ confidence interval in brackets are given.

Table 3: same as table 2 but for daily minimum temperature (TN)

Table 4: 50-year Return Levels (RLs) estimated from observed and simulated time series. For observations, the $95 \%$ confidence interval (in brackets) is obtained with the delta-method; for simulations, the given interval corresponds to the $2.5^{\text {th }}$ and $97.5^{\text {th }}$ percentiles of the distribution of the 100 obtained 50-year RLs

Table 5: mean and standard deviation estimated for the first part of the time series $\left(\mathrm{m}_{1}\right.$ and $\left.\mathrm{s}_{1}\right)$ and for the second part $\left(\mathrm{m}_{2}\right.$ and $\left.\mathrm{s}_{2}\right)$. First part corresponds to 19501980 for Berlin and 1962-1985 for Death Valley and second part to 1981-2009 for Berlin and 1986-2009 for Death Valley

Table 6: observed and simulated winter and summer mean and variance for the second period (1981-2009 for Berlin, 1986-2009 for Death Valley) according to each of the 2 approaches used to reconstruct temperature ( $\operatorname{sim} 1$ and $\operatorname{sim} 2$ : mean with $95 \%$ confidence interval in brackets)

Table 7: 50-year Return Levels (RLs) of winter cold TN in Berlin and summer warm TX in Death Valley estimated from observed and simulated time series for the second period (1981-2009 for Berlin, 1986-2009 for Death Valley) and according to both approaches to reconstruct temperature (simulations 1 and simulations 2). For observations, the $95 \%$ confidence interval (in brackets) is obtained with the delta-method; for simulations, the given interval corresponds to the $2.5^{\text {th }}$ and $97.5^{\text {th }}$ percentiles of the distribution of the 100 obtained 50-year RLs

\section{List of figures}

Figure 1: illustration of the derivation of the residuals from an observed daily temperature time series. The upper panel shows the original time series (top), its seasonality (middle) and trend (bottom) on the left and the time series of variance (top), its seasonality (middle) and trend (bottom) on the right, and the lower panel shows the obtained time series of residuals.

Figure 2: Q-Q plots of the summer and winter distributions for daily minimum temperature in Olekminsk (left panel) and daily maximum temperature in Death Valley (right panel). The solid line materializes the diagonal; the dots are for the mean simulation and the dashed lines for the $95 \%$ confidence interval of the simulations

Figure 3: observed (red) and simulated (black: mean -solid line- and 95\% confidence interval -dashed line-) mean annual cycle and daily standard deviation 
annual cycle for daily minimum temperature in Berlin (top panel) and daily

maximum temperature in Jacksonville (bottom panel)

Figure 4: distributions of the parameters of the Generalized Extreme Value (GEV) distribution fitted to the 100 simulations of the residuals (black): warm extremes (top panels: location $\mu$, scale $\sigma$ and shape $\xi$ from left to right) and cold extremes (bottom panels, same disposition) with their $2.5^{\text {th }}$ and $97.5^{\text {th }}$ percentiles (black dotted lines) and value of the same parameters obtained from the observations (red line). The top panels are for daily minimum temperature in Berlin and the bottom ones for daily maximum temperature in Death Valley.

Figure 5: frequencies of the 1- to more than 15-day long cold waves in Petropavlovsk (top panel) and 1- to more than15-day long heat waves in Charleston (bottom panel). A cold wave is obtained as consecutive days with daily minimum temperature lower than the $2^{\text {nd }}$ percentile of the observations and heat waves as consecutive days with daily maximum temperature higher than the $98^{\text {th }}$ percentile of the observations. The mean frequencies obtained from the simulations are represented by a solid black line, with the minimum and maximum frequencies in dotted black lines and the observed frequencies are represented by solid red lines.

Figure 6: distributions of the $1^{\text {st }}, 10^{\text {th }}, 50^{\text {th }}, 60^{\text {th }}, 90^{\text {th }}$ and $99^{\text {th }}$ percentiles of the 100 simulated temperature distributions estimated for daily minimum temperature in Berlin (top panels) over the second period (1981-2009) with the first approach (left panel) and the second approach (right panel), together with the estimation of the same percentiles from the observations over the same period (red line). The bottom panel is similar but for daily maximum temperature in Death Valley over period 1986-2009.

Figure 7: frequencies of the 1- to more than 15-day long cold waves in Berlin (top 2 panels) and 1- to more than 15-day long heat waves in Death Valley (bottom 2 32 panels). The definitions of cold and heat waves are the same as in figure 5 . The 33 mean frequencies obtained from the simulations are represented by a solid black 34 line, with the minimum and maximum frequencies in dotted black lines and the observed frequencies are represented by solid red lines. For each location, the top panel corresponds to the first simulation approach and the bottom one to the second one. 
1 Tables

2 Table 1

\begin{tabular}{|l|c|c|c|c|}
\hline \multirow{2}{*}{ Weather station } & \multicolumn{2}{|c|}{ Daily minimum temperature } & \multicolumn{2}{c|}{ Daily maximum temperature } \\
& period & $\begin{array}{l}\text { Mean annual } \\
\text { mean }\left({ }^{\circ} \mathrm{C}\right)\end{array}$ & period & $\begin{array}{l}\text { Mean annual } \\
\text { mean }\left({ }^{\circ} \mathrm{C}\right)\end{array}$ \\
\hline Biarritz & $1956-2009$ & 10.1 & $1956-2009$ & 17.7 \\
\hline Berlin & $1950-2009$ & 5.1 & $1950-2009$ & 13.4 \\
\hline Petropavlovsk & $1950-2009$ & -3.3 & $1950-2009$ & 6.9 \\
\hline Olekminsk & $1950-2009$ & -11.3 & - & - \\
\hline Death Valley & $1962-2009$ & 17.0 & $1962-2009$ & 32.8 \\
\hline Charleston & $1950-2009$ & 15.4 & $1950-2009$ & 23.0 \\
\hline Jacksonville & $1950-2009$ & 5.2 & $1950-2009$ & 17.5 \\
\hline Glasgow & $1950-2009$ & -0.7 & $1950-2009$ & 12.5 \\
\hline
\end{tabular}

$4 \quad$ Table 2

\begin{tabular}{|c|c|c|c|c|c|c|c|c|}
\hline & \multicolumn{8}{|c|}{ Daily maximum temperature TX } \\
\hline & \multicolumn{2}{|c|}{ mean } & \multicolumn{2}{|c|}{ variance } & \multicolumn{2}{|c|}{ skewness } & \multicolumn{2}{|c|}{ kurtosis } \\
\hline & obs & $\operatorname{sim}$ & obs & $\operatorname{sim}$ & obs & $\operatorname{sim}$ & obs & $\operatorname{sim}$ \\
\hline Berlin & 13.4 & $\begin{array}{c}13.4 \\
{[13.3 ; 13.5]}\end{array}$ & 84.1 & $\begin{array}{c}83.2 \\
{[80.1 ; 85.9]} \\
\end{array}$ & -0.03 & $\begin{array}{c}-0.02 \\
{[-0.06 ; 0.02]}\end{array}$ & -0.78 & $\begin{array}{c}-0.79 \\
{[-0.85 ;-0.72]}\end{array}$ \\
\hline Biarritz & 17.7 & $\begin{array}{c}17.7 \\
{[17.6 ; 17.8]}\end{array}$ & 37.1 & $\begin{array}{c}37.2 \\
{[35.9 ; 38.7]} \\
\end{array}$ & 0.07 & $\begin{array}{c}0.05 \\
{[-0.01 ; 0.10]}\end{array}$ & -0.06 & $\begin{array}{c}-0.23 \\
{[-0.33 ;-0.10]}\end{array}$ \\
\hline Petropavlovsk & 6.9 & $\begin{array}{c}6.9 \\
{[6.7 ; 7.1]}\end{array}$ & 237.8 & $\begin{array}{c}238.2 \\
{[233.6 ; 243.9]}\end{array}$ & -0.18 & $\begin{array}{c}-0.16 \\
{[-0.18 ;-0.13]}\end{array}$ & -1.03 & $\begin{array}{c}-1.08 \\
{[-1.11 ;-1.05]}\end{array}$ \\
\hline Olekminsk & - & - & - & - & - & - & - & - \\
\hline Death Valley & 32.8 & $\begin{array}{c}32.8 \\
{[32.6 ; 32.9]}\end{array}$ & 112.2 & $\begin{array}{c}112.2 \\
{[109.5 ; 114.8]}\end{array}$ & -0.08 & $\begin{array}{c}-0.07 \\
{[-0.10 ;-0.04]}\end{array}$ & -1.19 & $\begin{array}{c}-1.17 \\
{[-1.21 ;-1.11]}\end{array}$ \\
\hline Jacksonville & 17.5 & $\begin{array}{c}17.4 \\
{[17.3 ; 17.6]} \\
\end{array}$ & 137.1 & $\begin{array}{c}136.3 \\
{[133.2 ; 139.7]} \\
\end{array}$ & -0.43 & $\begin{array}{c}-0.39 \\
{[-0.41 ;-0.36]} \\
\end{array}$ & -0.82 & $\begin{array}{c}-0.87 \\
{[-0.91 ;-0.82]}\end{array}$ \\
\hline Glasgow & 12.5 & $\begin{array}{c}12.5 \\
{[12.2 ; 12.7]}\end{array}$ & 204.3 & $\begin{array}{c}202.8 \\
{[196.6 ; 208.7]}\end{array}$ & -0.38 & $\begin{array}{c}-0.33 \\
{[-0.37 ;-0.30]}\end{array}$ & -0.59 & $\begin{array}{c}-0.63 \\
{[-0.69 ;-0.58]}\end{array}$ \\
\hline Charleston & 23.0 & $\begin{array}{c}23.0 \\
{[22.9 ; 23.1]}\end{array}$ & 50.9 & $\begin{array}{c}50.7 \\
{[49.6 ; 52.0]} \\
\end{array}$ & -0.46 & $\begin{array}{c}-0.41 \\
{[-0.44 ;-0.39]}\end{array}$ & -0.48 & $\begin{array}{c}-0.57 \\
{[-0.63 ;-0.51]}\end{array}$ \\
\hline
\end{tabular}

5

6 Table 3

\begin{tabular}{|c|c|c|c|c|c|c|c|c|}
\hline & \multicolumn{8}{|c|}{ Daily minimum temperature TN } \\
\hline & \multicolumn{2}{|c|}{ mean } & \multicolumn{2}{|c|}{ variance } & \multicolumn{2}{|c|}{ skewness } & \multicolumn{2}{|c|}{ kurtosis } \\
\hline & obs & $\operatorname{sim}$ & obs & $\operatorname{sim}$ & obs & $\operatorname{sim}$ & obs & $\operatorname{sim}$ \\
\hline Berlin & 5.1 & $\begin{array}{c}5.1 \\
{[5.0 ; 5.2]}\end{array}$ & 49.1 & $\begin{array}{c}48.5 \\
{[46.4 ; 50.9]}\end{array}$ & -0.36 & $\begin{array}{c}-0.33 \\
{[-0.39 ;-0.26]}\end{array}$ & -0.21 & $\begin{array}{c}-0.28 \\
{[-0.48 ;-0.06]}\end{array}$ \\
\hline Biarritz & 10.1 & $\begin{array}{c}10.1 \\
{[10.0 ; 10.2]}\end{array}$ & 30.2 & $\begin{array}{c}30.1 \\
{[29.1 ; 31.1]} \\
\end{array}$ & -0.35 & $\begin{array}{c}-0.35 \\
{[-0.40 ;-0.31]} \\
\end{array}$ & -0.30 & $\begin{array}{c}-0.31 \\
{[-0.41 ;-0.21]} \\
\end{array}$ \\
\hline Petropavlovsk & -3.3 & $\begin{array}{c}-3.3 \\
{[-3.4 ;-3.1]} \\
\end{array}$ & 196.6 & $\begin{array}{c}196.7 \\
{[191.4 ; 202.9]} \\
\end{array}$ & -0.41 & $\begin{array}{c}-0.39 \\
{[-0.42 ;-0.37]} \\
\end{array}$ & -0.85 & $\begin{array}{c}-0.87 \\
{[-0.91 ;-0.81]} \\
\end{array}$ \\
\hline Olekminsk & -11.4 & $\begin{array}{c}-11.3 \\
{[-11.5 ;-11.1]} \\
\end{array}$ & 335.4 & $\begin{array}{c}334.9 \\
{[325.6 ; 344.7]}\end{array}$ & -0.30 & $\begin{array}{c}-0.29 \\
{[-0.31 ;-0.27]} \\
\end{array}$ & -1.14 & $\begin{array}{c}-1.13 \\
{[-1.17 ;-1.09]}\end{array}$ \\
\hline Death Valley & 16.9 & $\begin{array}{c}16.9 \\
{[16.8 ; 17.0]}\end{array}$ & 102.9 & $\begin{array}{c}102.7 \\
{[101.3 ; 104.3]}\end{array}$ & 0.02 & $\begin{array}{c}0.03 \\
{[0.00 ; 0.05]}\end{array}$ & -1.13 & $\begin{array}{c}-1.11 \\
{[-1.14 ;-1.09]}\end{array}$ \\
\hline
\end{tabular}




\begin{tabular}{|l|c|c|c|c|c|c|c|c|}
\hline Jacksonville & 5.2 & $\begin{array}{c}5.2 \\
{[5.0 ; 5.3]}\end{array}$ & 110.0 & $\begin{array}{c}109.7 \\
{[106.3 ; 113.9]}\end{array}$ & -0.33 & $\begin{array}{c}-0.31 \\
{[-0.35 ;-0.27]}\end{array}$ & -0.58 & $\begin{array}{c}-0.62 \\
{[-0.71 ;-0.53]}\end{array}$ \\
\hline Glasgow & -0.7 & $\begin{array}{c}-0.7 \\
{[-0.9 ;-0.5]}\end{array}$ & 147.1 & $\begin{array}{c}146.9 \\
{[141.1 ; 152.0]}\end{array}$ & -0.58 & $\begin{array}{c}-0.54 \\
{[-0.58 ;-0.50]}\end{array}$ & -0.25 & $\begin{array}{c}-0.30 \\
{[-0.40 ;-0.19]}\end{array}$ \\
\hline Charleston & 15.4 & $\begin{array}{c}15.4 \\
{[15.3 ; 15.5]}\end{array}$ & 60.0 & $\begin{array}{c}60.0 \\
{[58.6 ; 61.6]}\end{array}$ & -0.40 & $\begin{array}{c}-0.37 \\
{[-0.40 ;-0.34]}\end{array}$ & -0.86 & $\begin{array}{c}-0.90 \\
{[-0.94 ;-0.85]}\end{array}$ \\
\hline
\end{tabular}

2 Table 4

\begin{tabular}{|l|c|c|c|c|}
\hline \multicolumn{4}{|l}{ TX } & \multicolumn{1}{l|}{ TN } \\
\hline & observations & simulations & observations & simulations \\
\hline Berlin & $38.2[37.1 ; 39.2]$ & $39.8[38.8 ; 41.0]$ & $-23.4[-25.5 ;-21.0]$ & $-26.5[-31.5 ;-22.9]$ \\
\hline Biarritz & $39.6[38.8 ; 40.4]$ & $41.0[39.0 ; 43.5]$ & $-9.4[-12.2 ;-6.6]$ & $-11.0[-12.6 ;-9.7]$ \\
\hline Petropavlovsk & $38.5[37.6 ; 39.5]$ & $41.5[39.3 ; 44.8]$ & $-43.7[-45.2 ;-42.1]$ & $-48.7[-52.5 ;-45.3]$ \\
\hline Olekminsk & - & - & $-56.3[-57.8 ;-54.8]$ & $-58.8[-61.4 ;-56.2]$ \\
\hline Death Valley & $54.3[53.5 ; 55.1]$ & $55.2[54.3 ; 56.1]$ & $-6.4[-7.5 ;-5.3]$ & $-7.4[-8.8 ;-6.0]$ \\
\hline Jacksonville & $41.8[40.3 ; 43.3]$ & $43.1[41.5 ; 44.5]$ & $-29.5[-31.3 ;-27.7]$ & $-33.8[-38.5 ;-30.6]$ \\
\hline Glasgow & $42.0[41.1 ; 42.8]$ & $45.5[44.3 ; 46.9]$ & $-42.9[-44.4 ;-41.4]$ & $-46.9[-50.4 ;-44.0]$ \\
\hline Charleston & $39.5[38.6 ; 40.4]$ & $40.3[39.5 ; 41.2]$ & $-11.3[-13.7 ;-9.0]$ & $-8.8[-10.0 ;-7.5]$ \\
\hline
\end{tabular}

3

4 Table 5

\begin{tabular}{|l|c|c|c|c|}
\hline & $\mathrm{m}_{1}\left({ }^{\circ} \mathrm{C}\right)$ & $\mathrm{m}_{2}\left({ }^{\circ} \mathrm{C}\right)$ & $\mathrm{s}_{1}\left({ }^{\circ} \mathrm{C}\right)$ & $\mathrm{s}_{2}\left({ }^{\circ} \mathrm{C}\right)$ \\
\hline TN Berlin & 4.7 & 5.5 & 7.0 & 6.9 \\
\hline $\begin{array}{l}\text { TX Death } \\
\text { Valley }\end{array}$ & 32.3 & 33.2 & 10.4 & 10.7 \\
\hline
\end{tabular}

5

6

7 Table 6

\begin{tabular}{|l|c|c|c|c|c|c|c|c|c|c|c|c|}
\hline & \multicolumn{9}{|c|}{ winter } & \multicolumn{5}{c|}{ summer } \\
\hline & \multicolumn{3}{|c|}{ mean } & \multicolumn{3}{c|}{ variance } & \multicolumn{3}{c|}{ mean } & \multicolumn{3}{c|}{ variance } \\
\hline & obs & $\operatorname{sim} 1$ & $\operatorname{sim} 2$ & obs & $\operatorname{sim} 1$ & $\operatorname{sim} 2$ & obs & $\operatorname{sim} 1$ & $\operatorname{sim} 2$ & obs & sim1 & $\operatorname{sim} 2$ \\
\hline TN & -1.7 & -2.0 & -1.8 & 25.0 & 25.2 & 23.2 & 13.1 & 13.2 & 13.0 & 8.7 & 8.2 & 9.1 \\
Berlin & & {$[-2.7 ;$} & {$[-2.5 ;$} & & {$[20.8 ;$} & {$[18.9 ;$} & & {$[12.9 ;$} & {$[12.8 ;$} & & {$[7.5 ;$} & {$[8.2 ;$} \\
& & $-1.4]$ & $-1.2]$ & & $29.8]$ & $28.4]$ & & $13.4]$ & $13.2]$ & & $8.9]$ & $9.9]$ \\
\hline TX & 20.2 & 20.7 & 20.2 & 18.7 & 18.2 & 18.4 & 45.7 & 45.4 & 45.7 & 15.0 & 13.6 & 14.5 \\
Death & & {$[20.4 ;$} & {$[19.9 ;$} & & {$[15.5 ;$} & {$[15.9 ;$} & & {$[45.1 ;$} & {$[45.3 ;$} & & {$[11.7 ;$} & {$[12.6 ;$} \\
Valley & & $21.1]$ & $20.6]$ & & $20.8]$ & $21.2]$ & & $45.8]$ & $46.0]$ & & $16.1]$ & $17.1]$ \\
\hline
\end{tabular}

8

9 Table 7

\begin{tabular}{|l|l|l|l|}
\hline & observations & simulations 1 & simulations 2 \\
\hline $\begin{array}{l}\text { Cold extremes } \\
\text { Berlin }\end{array}$ & $-21.6[-24.7 ;-18.5]$ & $-28.2[-37.3 ;-22.3]$ & $-26.7[-37.5 ;-21.5]$ \\
\hline $\begin{array}{l}\text { Warm extremes } \\
\text { Death Valley }\end{array}$ & $53.2[52.2 ; 54.1]$ & $54.3[53.2 ; 55.6]$ & $55.1[54.1 ; 56.2]$ \\
\hline
\end{tabular}

10 
1 Figures

2 Figure1

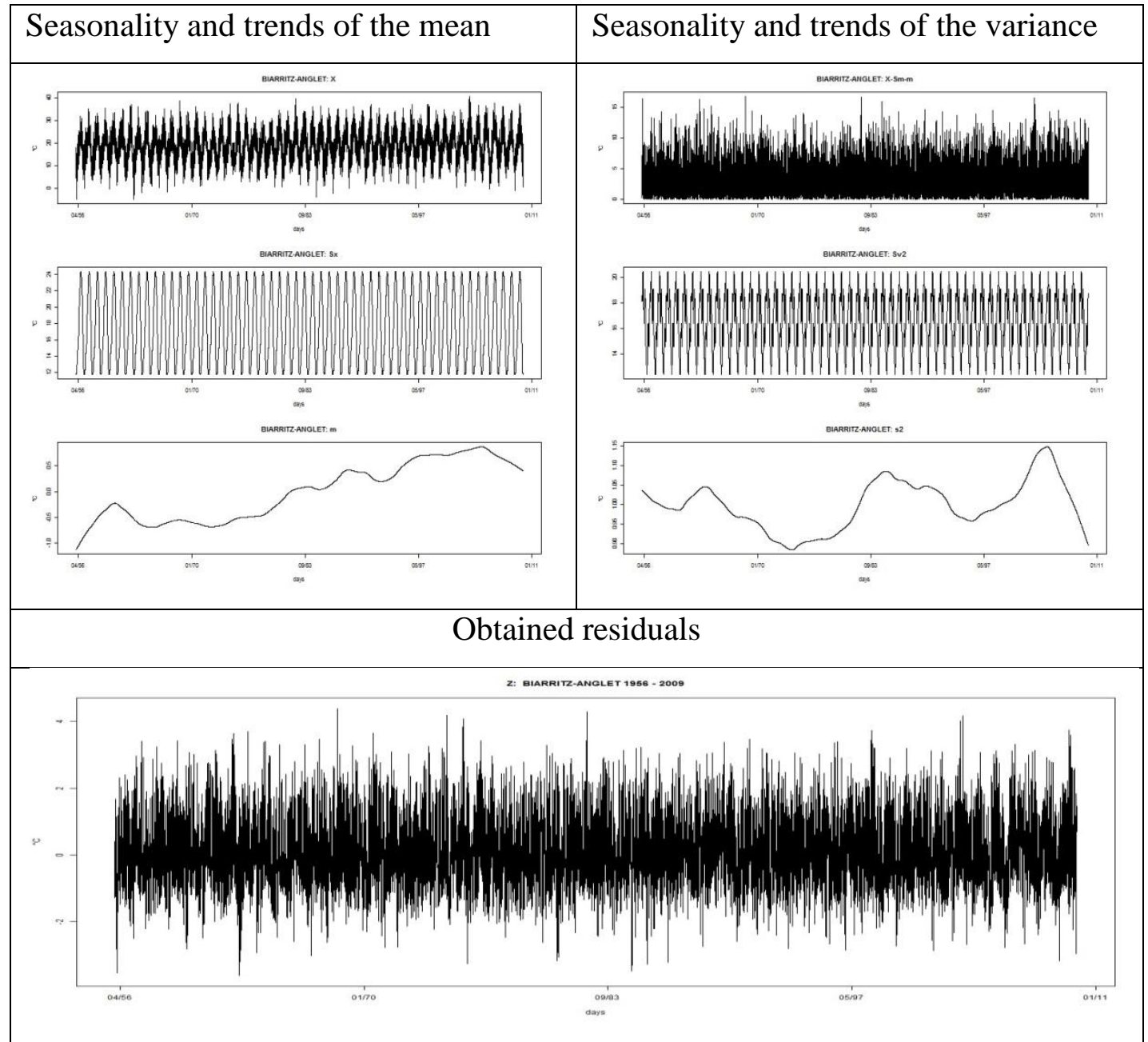

3

4 
$1 \quad$ Figure 2

2

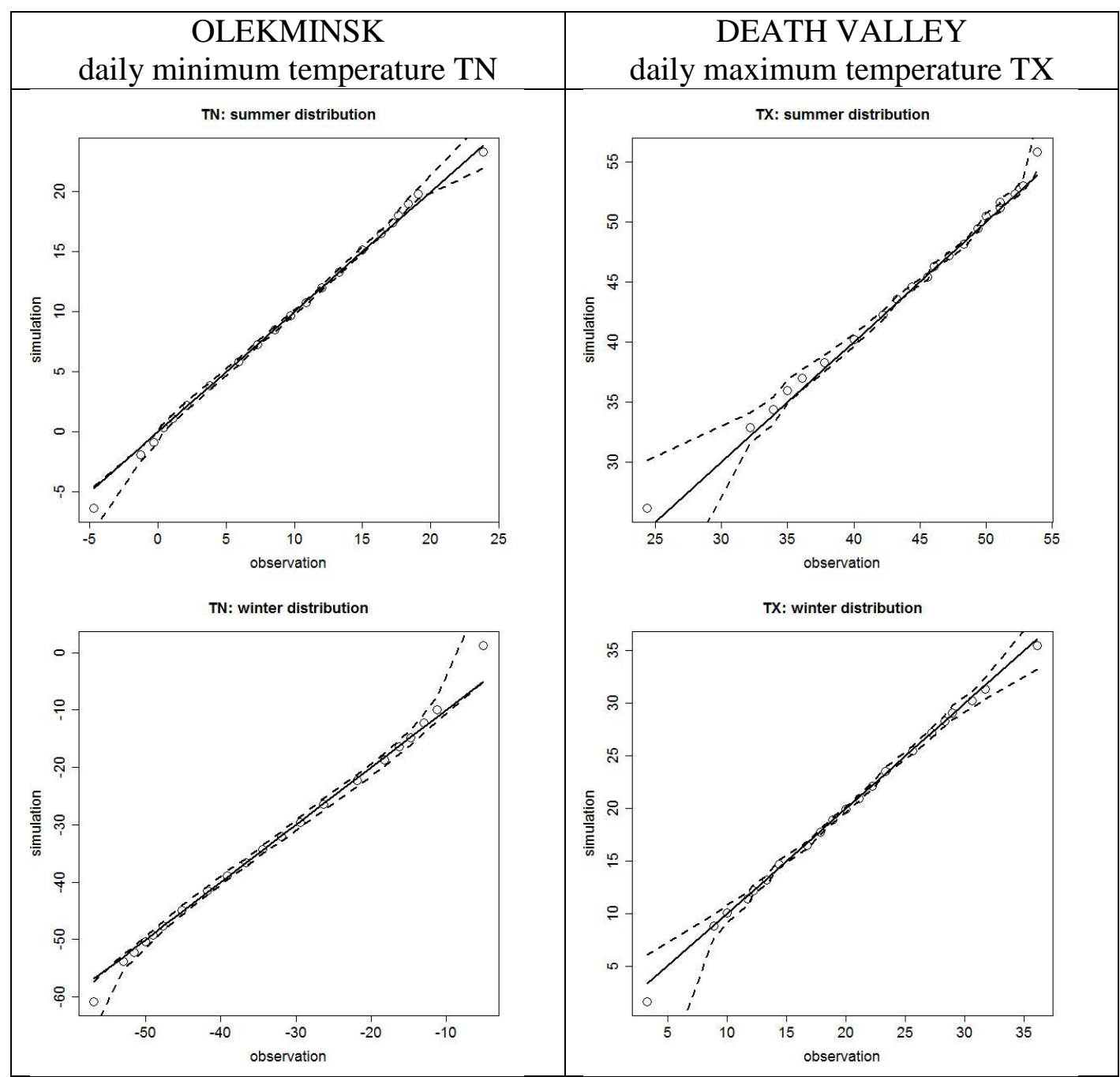

3

4 
1 Figure 3

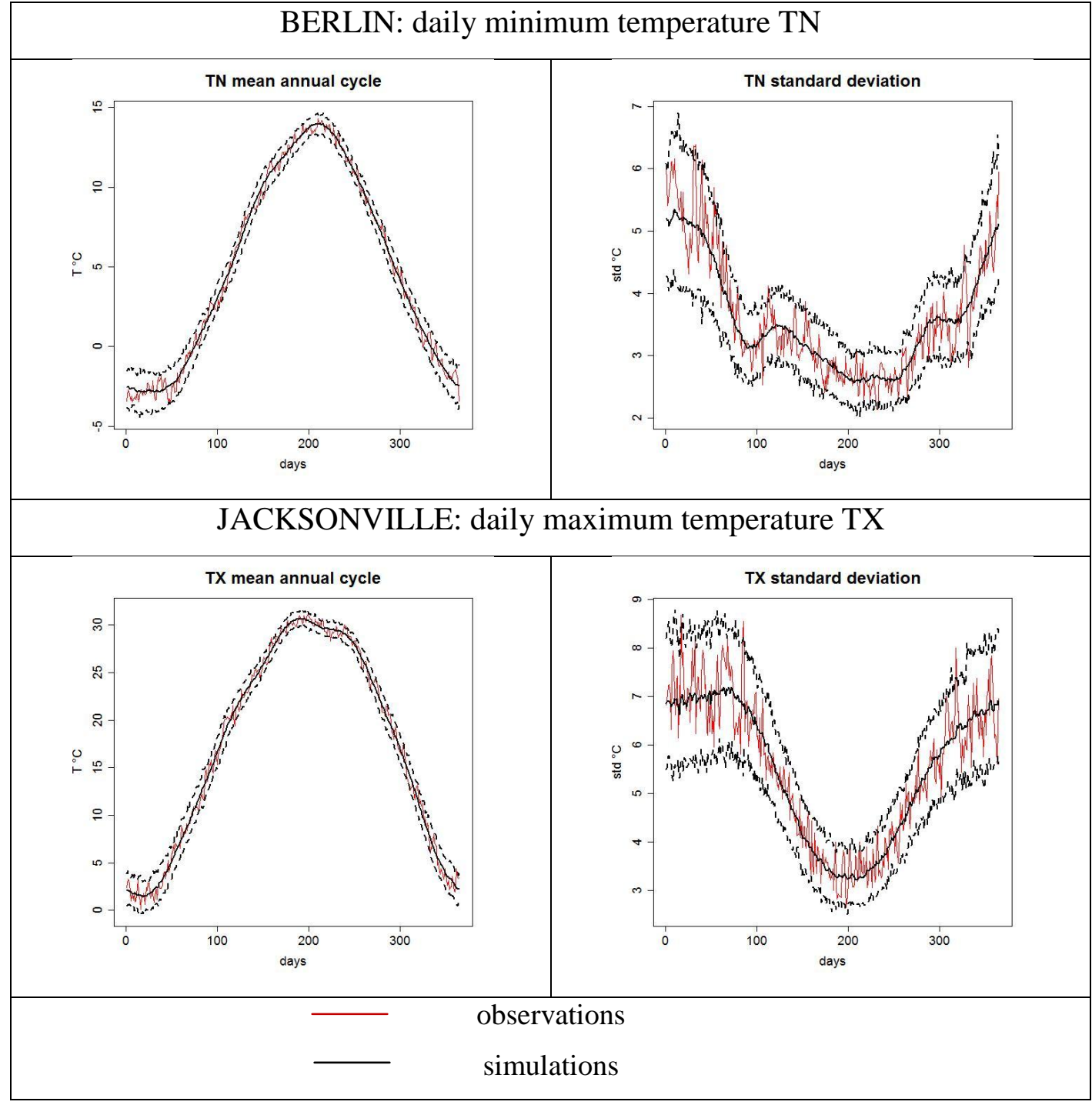


Figure 4

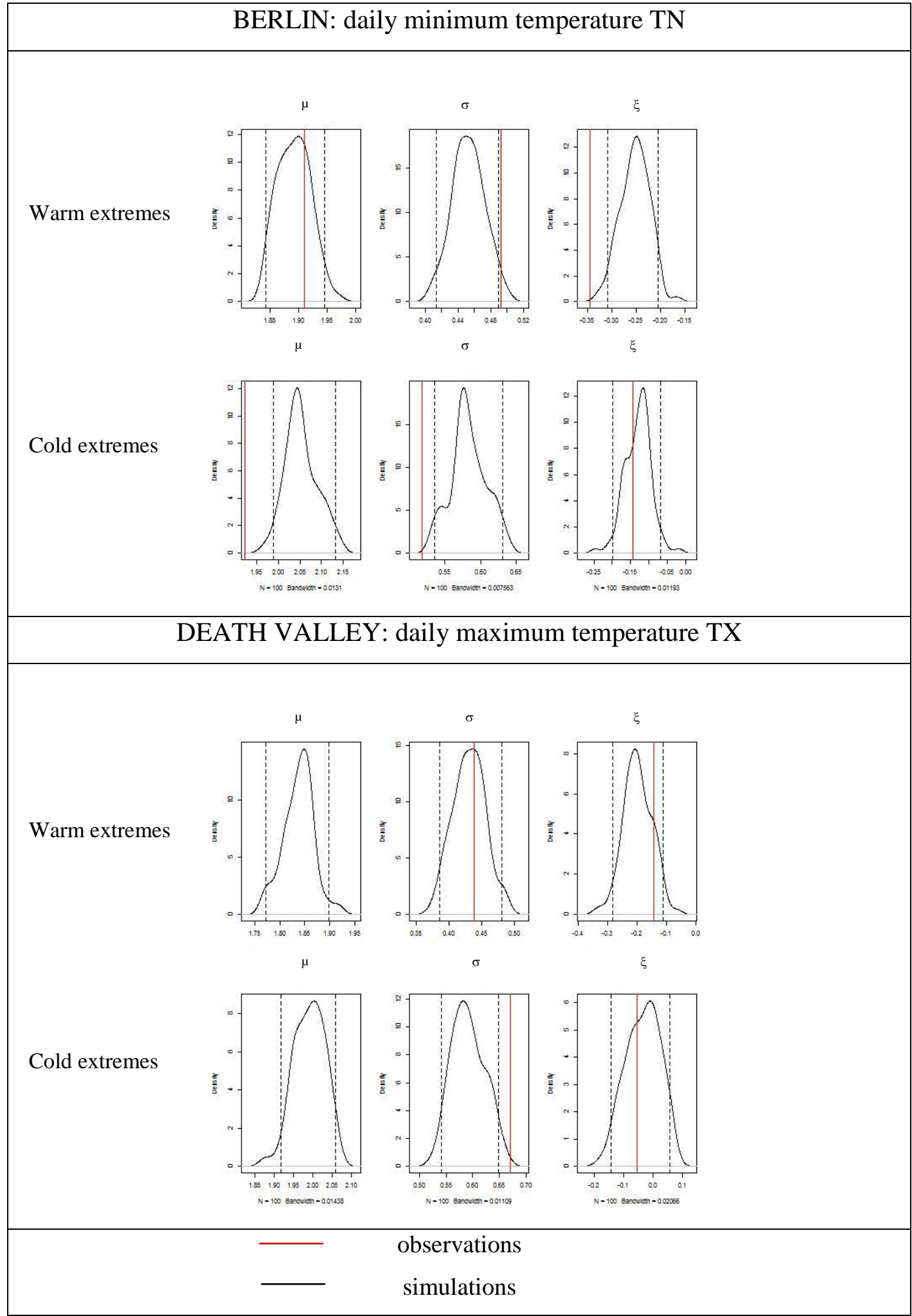


1 Figure 5

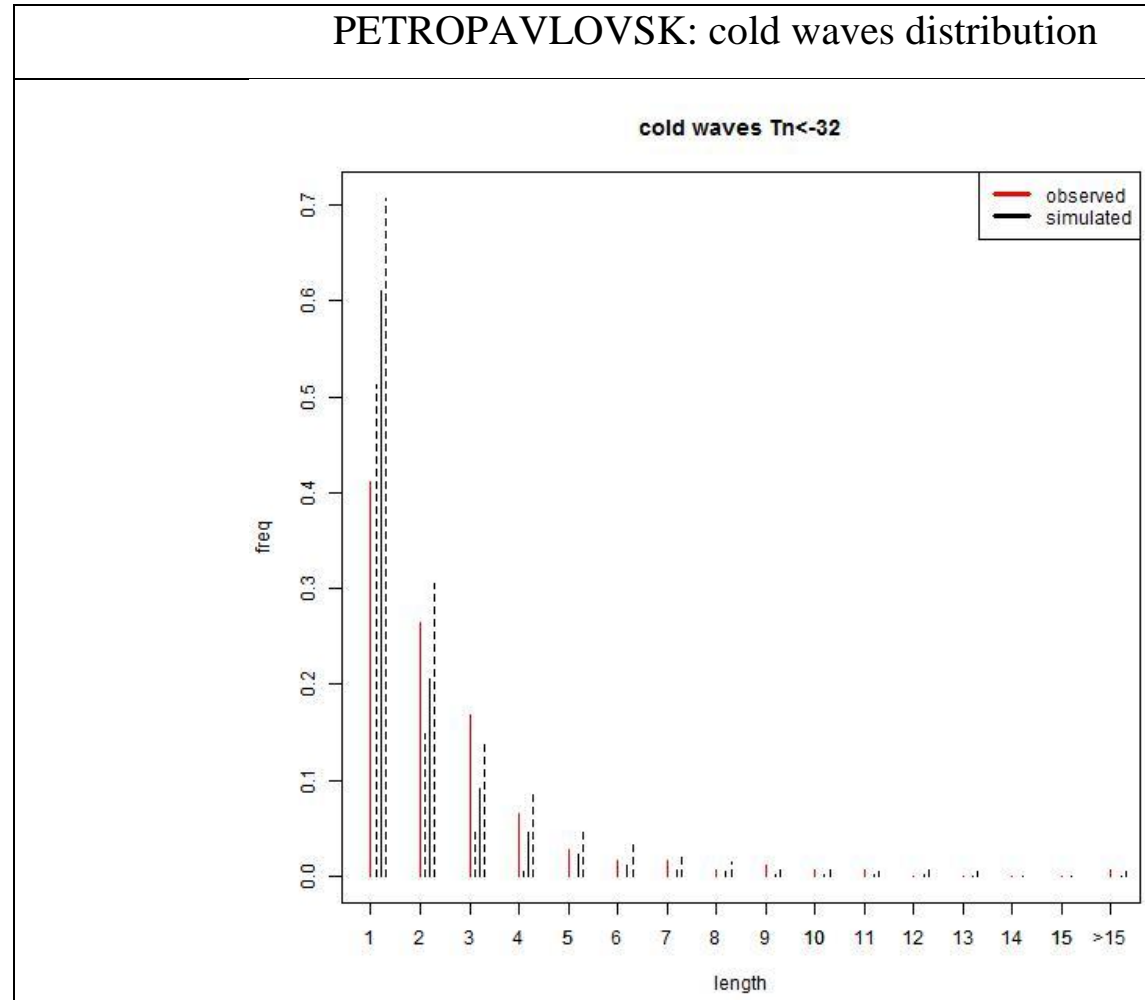

\section{CHARLESTON: heat waves distribution}

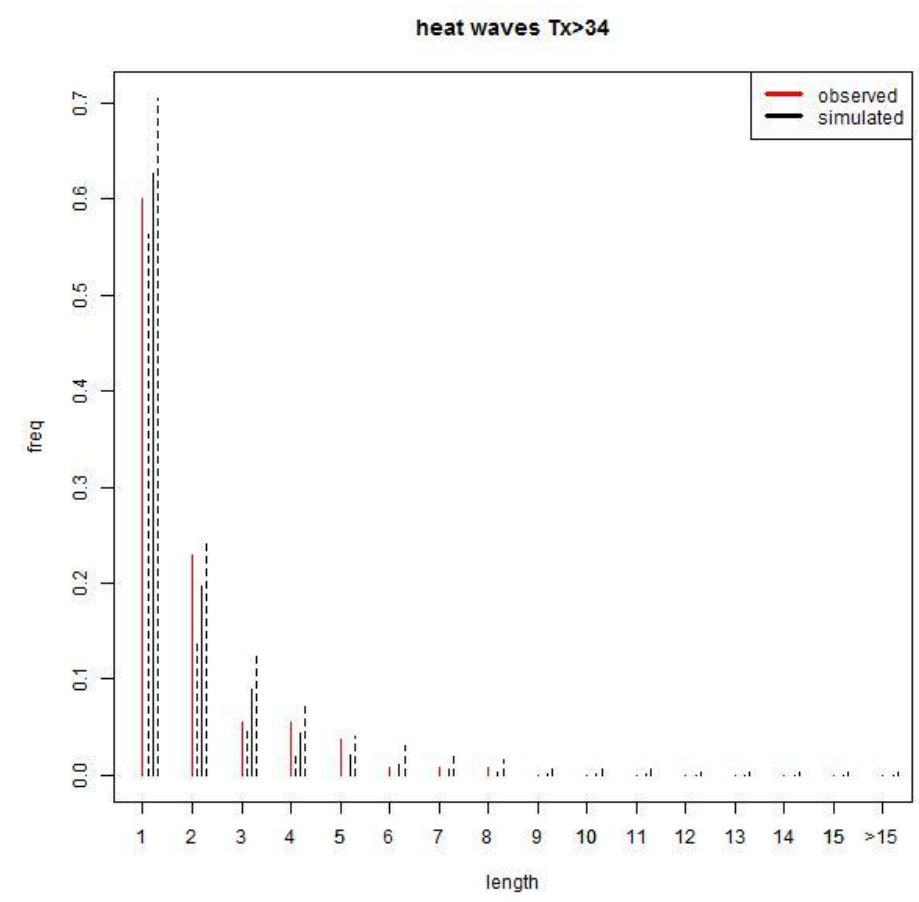

observations

simulations 
$1 \quad$ Figure 6

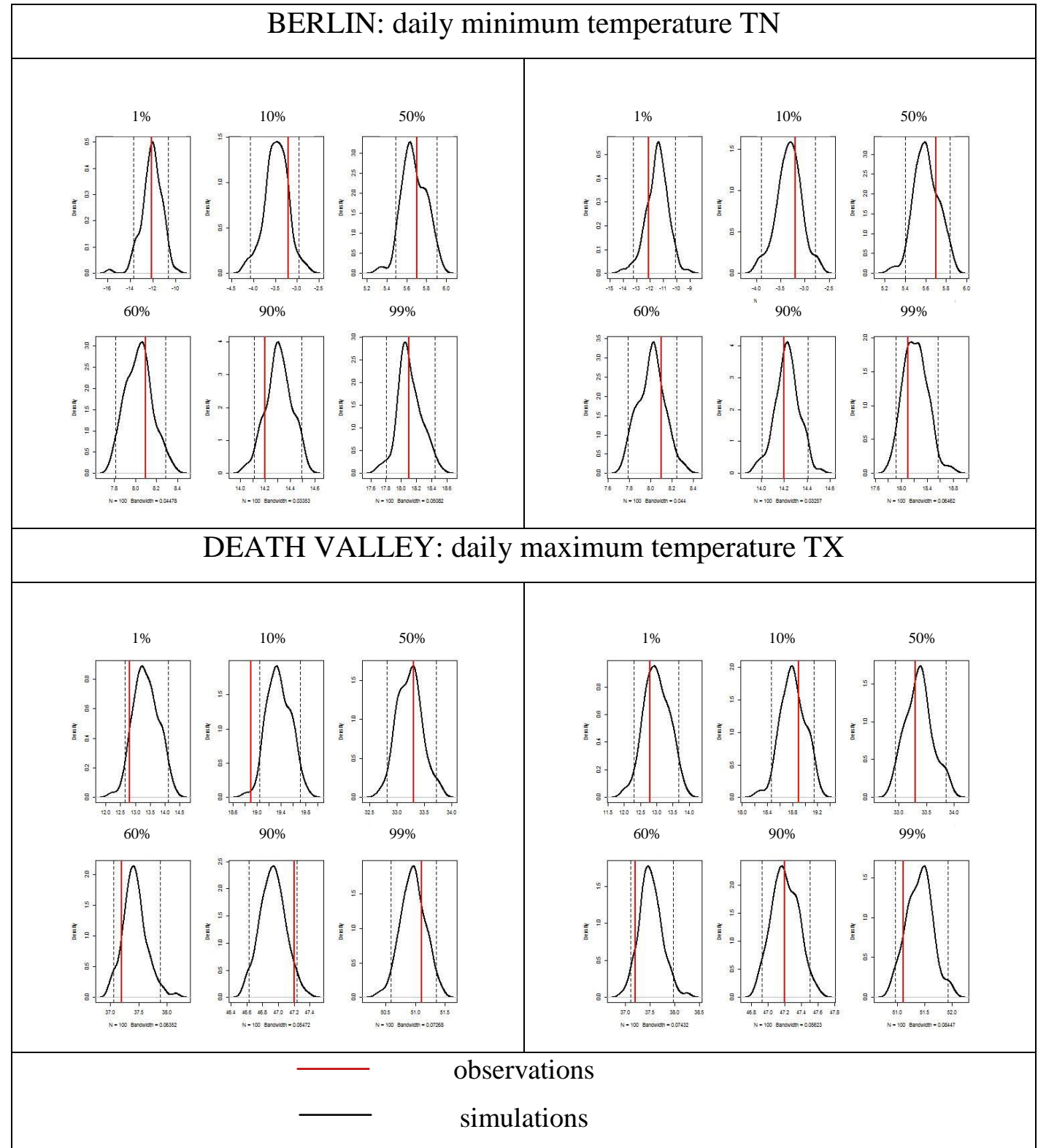

2 
$1 \quad$ Figure 7

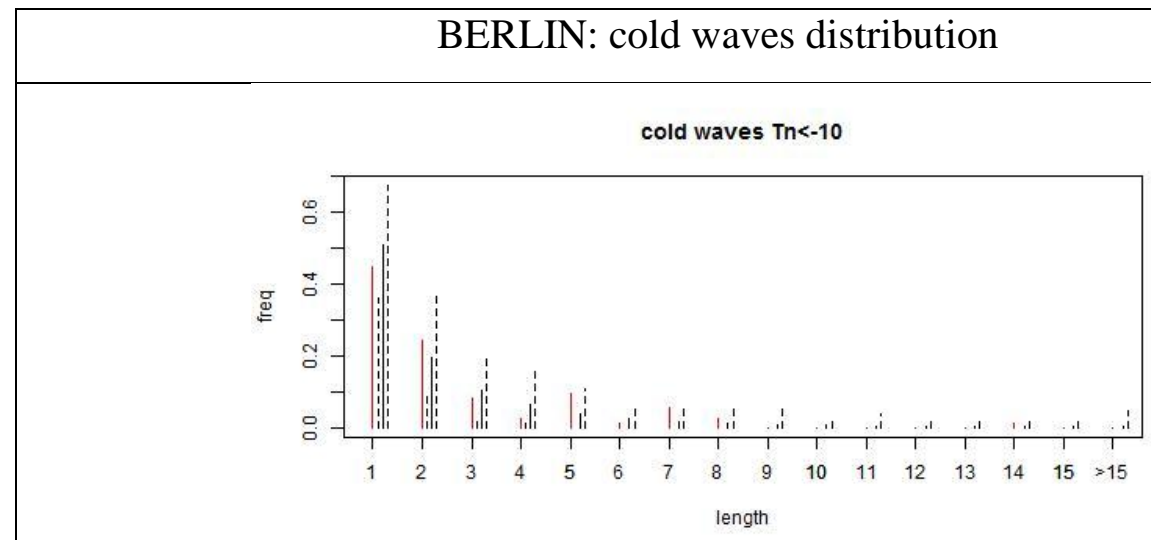

cold waves $\mathrm{Tn}<-10$

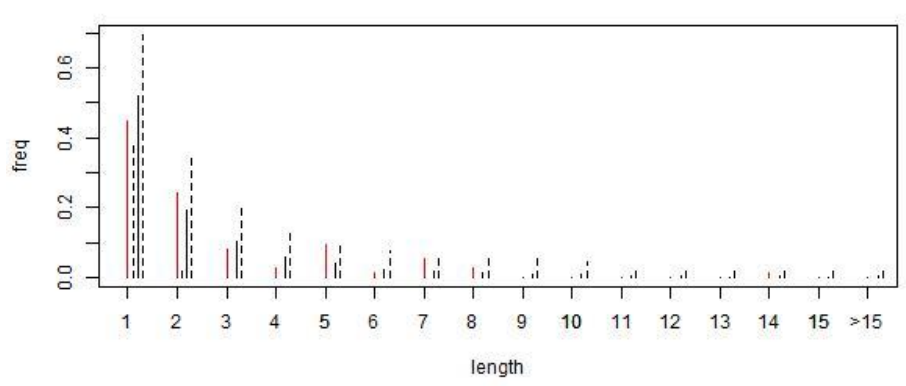

DEATH VALLEY: heat waves distribution

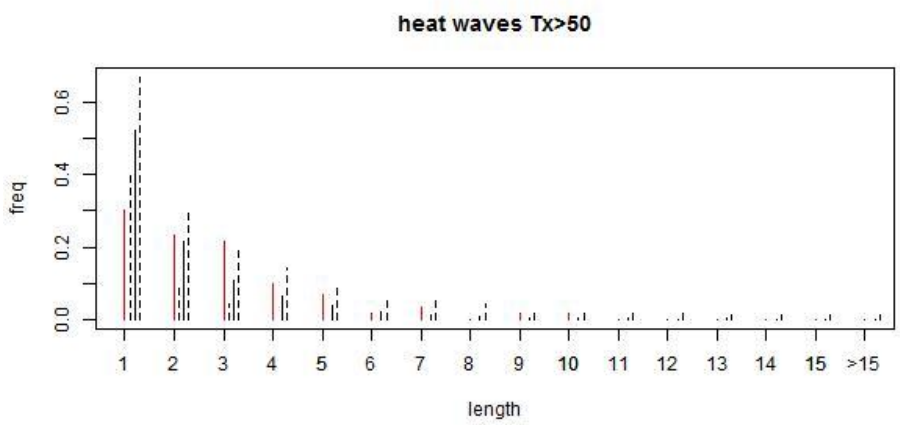

heat waves $T x>50$

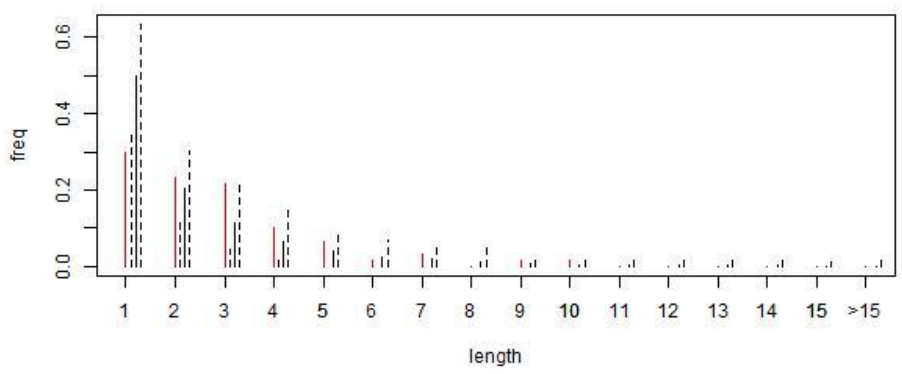

observations

simulations 